\title{
KAJIAN HASIL PREDIKSI KONSENTRASI AEROSOL PM10 DARI DATA ECMWF DENGAN HASIL PENGUKURAN DI STASIUN PEMANTAU ATMOSFER GLOBAL BUKIT KOTOTABANG (AGAM) DAN KOTA PADANG
}

\section{STUDY OF THE RESULTS AEROSOL PM10 CONCENTRATION PREDICTION FROM ECMWF DATA WITH MEASUREMENT RESULTS IN THE KOTOTABANG GLOBAL ATMOSPHERE WATCH STATION (AGAM) AND PADANG OF CITY}

\author{
Sri Yanti Lisha ${ }^{1 *}$, Nofriya ${ }^{2}$, Darmadi ${ }^{3}$ \\ ${ }^{1-2}$ Sekolah Tinggi Teknologi Industri (STTIND) Padang \\ ${ }^{3}$ Stasiun Pemantau Atmosfer Global Bukit Kototabang
}

Naskah masuk: 09 Maret $2021 \quad$ Naskah diperbaiki: 20 Maret $2021 \quad$ Naskah diterima: 24 Maret 2021

\begin{abstract}
ABSTRAK
Emisi polutan udara yang bersumber dari kebakaran hutan dan lahan serta dari transportasi di wilayah perkotaan menjadi perhatian baik bagi pemangku kepentingan dan masyarakat. Salah satu jenis polutan udara yang sering menjadi indikator utama adalah particulate matter 10 micron (PM10). Sedikitnya titik lokasi pengukuran konsentrasi PM10 menyebabkan ketersediaan data dan informasi polutan udara ini terbatas. Penelitian ini bertujuan untuk melakukan kajian terhadap penggunaan data dari model ECMWF sebagai prediksi untuk konsentrasi PM10 di dua lokasi, yaitu di Stasiun Pemantau Atmosfer Global Bukit Kototabang dan Kota Padang. Metode penelitian yang digunakan mengacu pada analisis data secara kuantitatif menggunakan metode korelasi dan statistik deskriptif. Hasil dari penelitian ini menunjukkan konsentrasi PM10 dengan menggunakan data ECMWF terhadap data observasi di kota Padang menunjukkan nilai selisih 25\% $(\mathrm{H}-1), 20 \%(\mathrm{H}-$ $2)$, dan $17 \%(\mathrm{H}-3)$, dan nilai prediksi terbaik adalah untuk data ECMWF pada $\mathrm{H}-3$. Sementara itu nilai prediksi konsentrasi PM10 dengan menggunakan data ECMWF terhadap data observasi di Bukit Kototabang menunjukan nilai $12 \%(\mathrm{H}-1), 23 \%(\mathrm{H}-2)$, dan $24 \% \quad(\mathrm{H}-3)$. Hasil nilai prediksi terbaik konsentrasi PM10 di Bukit Kototabang adalah untuk data ECMWF pada $\mathrm{H}-1$. Secara umum, konsentrasi PM10 dan hasil observasi menunjukkan profil yang sama, meskipun hasil dari ECMWF memberikan nilai konsentrasi yang berbeda di dua lokasi penelitian.

Kata kunci: PM10, ECMWF, Bukit Kototabang, Kota Padang.
\end{abstract}

\section{ABSTRACT}

Air pollutant emissions originating from forest and land fires as well as from transportation in urban areas are of concern to both stakeholders and the general public. One type of air pollutants that is considered as the main indicator of air pollution is particulate matter 10 micron (PM10). The limited number of locations for measuring PM10 concentrations in the field causes the availability of data and information on air pollutants. This study aims to study the use of data from the ECMWF model as a prediction for PM10 concentration in two locations, namely the Bukit Kototabang Global Atmospheric Monitoring Station and the City of Padang. The research method used refers to quantitative data analysis using correlation methods and descriptive statistics. The results of this study indicate that the concentration of PM10 using ECMWF data on observational data in the city of Padang shows a difference of $25 \%(\mathrm{H}-1), 20 \%(\mathrm{H}-2)$, and $17 \%$ $(\mathrm{H}-3)$, and the best predictive value. is for ECMWF data on H-3. Meanwhile, the prediction value of PM10 concentration using ECMWF data on observation data at the Bukit Kototabang Station shows a value of $12 \%(\mathrm{H}-$ 1), $23 \%(H-2)$, and $24 \%(H-3)$. The best prediction value for PM10 concentration at the Bukit Kototabang Station is for ECMWF data on $\mathrm{H}-1$. In general, the PM10 concentration and the observed results show the same profile even though on average the results from the ECMWF provide different concentration values in the two study locations. Keywords: PM10, ECMWF, Bukit Kototabang, Padang City. 


\section{Pendahuluan}

Dalam beberapa dekade terakhir, Indonesia sering kali dihadapkan dengan masalah yang berhubungan dengan terbakarnya hutan dan lahan (karhutla), khususnya untuk daerah yang memiliki tutupan vegetasi yang luas dan/atau didominasi oleh lahan gambut, seperti Sumatera dan Kalimantan. Diperkirakan hampir 9,75 juta hektar hutan dan lahan di wilayah Indonesia terdampak oleh peristiwa ini, terutama akibat kejadian karhutla tahun 1997 dan 2015 [1][2].

Menurut [3], kejadian karhutla yang terjadi di Indonesia tahun 1997/1998 adalah salah satu bencana lingkungan yang paling dahsyat pada abad kedua puluh, berdasarkan biaya yang berhubungan dengan kerusakan, serta jumlah karbon dan polusi yang dipancarkan dari pembakaran. Karhutla memainkan peran penting dalam perubahan senyawa kimia yang ada di atmosfer dan reaksi-reaksi kimia yang menyebabkan pembentukan polutan udara [4]. Data dari World Health Organization (WHO) atau Organisasi Kesehatan Dunia, 9 dari 10 orang di dunia menghirup udara yang tingkat polusinya melampaui ambang batas yang dianjurkan untuk kesehatan [5].

Tingkat konsentrasi polutan di suatu tempat/daerah tidak hanya disebabkan oleh banyaknya sumber emisi seperti yang terjadi pada kejadian karhutla, tetapi juga dipengaruhi oleh laju perubahan fisik dan kimia dari pencemar itu sendiri serta distribusi dan penyebaran polutan tersebut di udara. Ini terutama sering dijumpai di kawasan perkotaan dengan tingkat kepadatan penduduk dan frekuensi kendaraan bermotor yang tinggi. Oleh karena itu, untuk mengetahui sampai mana emisi dari suatu sumber dapat dikatakan membahayakan atau dapat menimbulkan gangguan, perlu lebih jauh pemahaman mengenai karakteristik atmosfer yang sangat erat hubungannya dengan kondisi meteorologi setempat [6]; [7].

Stasiun Pemantau Atmosfer Global Bukit Kotabang merupakan salah satu tempat untuk mengukur referensi udara bersih dunia. Stasiun ini terletak pada koordinat $100,32^{\circ}$ Bujur Timur, $0,20^{\circ}$ Lintang Selatan di ketinggian $864,5 \mathrm{~m}$ di atas muka laut. Stasiun Pemantau Atmosfer Global Bukit Kototabang dipilih sebagai tempat untuk mengukur referensi udara bersih, karena bukit ini berada jauh dari sumber-sumber pencemaran udara antropogenik seperti industri, jalan raya dan pemukiman. Jalan raya dan pemukiman yang merupakan salah satu sumber pencemaran udara antropogenik berada di kaki bukit dengan jarak sekitar $3 \mathrm{~km}$ dari Bukit Kototabang, sehingga tempat ini diharapkan ideal untuk mengukur referensi udara bersih. Meskipun secara asumsi tempat ini cocok untuk pengamatan udara bersih, namun udara bukanlah sistem yang dapat diisolasi, sehingga polutan dari luar masih mungkin masuk ke kawasan udara Stasiun Pemantau Atmosfer Global Bukit Kototabang [8].

Kota Padang adalah kota terbesar di pantai barat Pulau Sumatera dan ibu kota provinsi Sumatera Barat. Kota ini merupakan pintu gerbang barat Indonesia dari Samudra Hindia. Menurut Perda No. 10 Tahun 2005 tentang luas Kota Padang mempunyai luas wilayah 1.414,96 $\mathrm{Km}^{2}$ Secara geografis wilayah Kota Padang

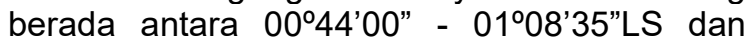
10005'05" - 100³4'09" BT, dengan Batas Utara: Kabupaten Padang Pariaman, Batas Selatan: Kabupaten Pesisir Selatan, Batas Timur: Kabupaten Solok, Batas Barat: Samudra Hindia.

Kondisi Kota Padang yang berada di pesisir pantai Sumatera dan tingginya frekuensi kendaraan bermotor dan banyaknya kawasan industri menyebabkan wilayah ini rentan terhadap peningkatan konsentrasi polutan udara. [9] melakukan kajian terhadap faktor meteorologi da karakteristik lalu lintas terhadap dispersi konsentrasi PM10 di Kota Padang dan menemukan bahwa penurunan kualitas udara sebesar $15 \%$ yang dirasakan di kawasan yang berada di pinggiran jalan raya. Penelitian senada sebelumnya juga dilakukan oleh [10] yang menganalisis peningkatan konsentrasi PM10 sebesar $43 \%$ di kawasan sekitar jalan utama Kota Padang. Sementara itu, [11] melakukan kajian mengenai pengaruh arah angin terhadap dispersi konsentrasi PM10 di area pinggiran jalan di Kota Padang dan mendapatkan bahwa wilayah ini sangat dipengaruhi oleh tingginya aktivitas kendaraan bermotor. Dampak terhadap peningkatan konsentrasi PM10 di Kota Padang ini dirasakan oleh masyarakat, terutama pedagang kaki lima [11] dan pengguna jalan [12]; [13].

Kondisi yang kontras dapat diamati di Stasiun Pemantau Atmosfer Global Bukit Kototabang, oleh karena keberadaannya yang minim dipengaruhi oleh sumber emisi, Stasiun ini dijadikan sebagai stasiun referensi udara bersih di Indonesia [14]. Stasiun ini telah melakukan pengukuran konsentrasi PM10 sejak tahun 2004 dan telah memberikan informasi kondisi kualitas udara kepada publik. Kejadian karhutla 
yang terjadi di Pulau Sumatera sering kali dapat terpantau di Bukit Kototabang dengan terindikasinya peningkatan konsentrasi PM10 yang terukur.

Beberapa penelitian dan gambaran umum di atas mengemukakan pentingnya informasi mengenai konsentrasi PM10 di Kota Padang. Namun demikian, informasi yang diberikan baru sebatas hasil kajian yang dilakukan terbatas pada periode pengukuran dalam kegiatan penelitian. Merujuk dari rekomendasi dari penelitian-penelitian tersebut, informasi mengenai peningkatan konsentrasi PM10 memberikan dampak buruk bagi kesehatan [12]; [15]; [16]. Oleh karena itu, prediksi terhadap konsentrasi PM10 yang diakibatkan oleh peningkatan emisinya di udara sangat vital untuk memformulasi strategi yang dapat dilakukan guna mengurangi tingkat pencemaran PM10 di Kota Padang.

Informasi prediksi konsentrasi PM10 diperoleh dari hasil pemodelan komputasi. Salah satu sumber informasi yang sering digunakan adalah data yang bersumber dari European Centre for Medium-Range Weather Forecasts (ECMWF). ECMWF memberikan informasi prediksi konsentrasi polutan udara, termasuk PM10 secara harian dalam jangka waktu 5 hari ke depan [19], menjadikan informasi yang diberikan sangat bermanfaat untuk digunakan sebagai dasar analisis kondisi kualitas udara dalam jangka waktu beberapa hari ke depan. Keunggulan lain dari data ECMWF adalah simulasinya yang komprehensif dengan melibatkan kondisi meteorologi dan komposisi kimia atmosfer termutakhir dalam proses pemodelannya [17].

Adapun tujuan dari penelitian ini adalah untuk menganalisis hasil prediksi konsentrasi PM10 yang dihasilkan oleh European Centre for Medium-Range Weather Forecast (ECMWF) dan bagaimana kondisi kualitas udara berdasarkan konsentrasi PM10, dan mengevaluasi hasil prediksi PM10 ECMWF dengan hasil pengukuran yang dilakukan di Stasiun Pemantau Atmosfer Global Bukit Kototabang Kabupaten Agam dan Kota Padang.

\section{Metode Penelitian}

Penelitian ini dilakukan untuk menganalisis prediksi konsentrasi PM10 berdasarkan hasil simulasi ECMWF dengan konsentrasi PM10 yang terukur di lapangan. Penelitian ini menggunakan pendekatan kuantitatif karena menggunakan data dalam bentuk angka dan analisis statistik untuk menjawab permasalahan penelitian yang dirumuskan. Jenis penelitian kuantitatif adalah metode korelasi karena membandingkan data dari berbagai sumber dengan menggunakan pendekatan korelasi statistik [18].

Analisis statistik yang digunakan dalam penelitian ini adalah Statistik Deskriptif, yang mana menurut [19], Statistik Deskriptif adalah data yang dikumpulkan dalam sampel yang dapat memberikan gambaran atau deskripsi karakteristik melalui nilai rata-rata, nilai maksimum dan minimum, serta standar deviasi. Mean menunjukkan nilai rata-rata sampel, sedangkan nilai minimum, nilai maksimum, dan standar deviasi menunjukkan penyebaran data dari data penelitian yang digunakan.

Data yang digunakan dalam penelitian ini merupakan data sekunder, yang didapatkan dari hasil pengamatan di lapangan yaitu di Stasiun Pemantau Atmosfer Global Bukit Kototabang Kabupaten Agam dan Kota Padang serta data prediksi hasil ECMWF pada Februari s/d April 2020, dan mencakup data koordinat untuk penentuan lokasi serta mempelajari literatur yang berhubungan dengan penelitian ini yang berisi tentang petunjuk dan semua informasi yang berguna dalam pelaksanaan penelitian ini. Data-data tersebut antara lain:

1. Hasil prediksi PM10 dengan resolusi data per jam yang dikeluarkan oleh ECMWF, data ini diunduh dari laman: $\mathrm{ftp}: / /$ dissemination.ecmwf.int.

2. Hasil pengukuran konsentrasi PM10 di Stasiun Pemantau Atmosfer Global Bukit Kototabang dengan resolusi data per jam. Pengukuran PM10 ini dengan menggunakan instrumen MetOne BAM 1020. Alat ini dioperasikan secara kontinyu dan data yang dihasilkan telah terekam secara otomatis pada database.

3. Hasil pengukuran PM10 di Kota Padang dengan menggunakan alat Air Quality Monitoring System (AQMS), dengan resolusi data per jam.

\section{Analisis Data Bias (RMSE)}

RMSE (Root Mean Square Error) merupakan metode untuk mengestimasi besarnya kesalahan pengukuran, dan menurut [20] merupakan parameter yang digunakan untuk mengevaluasi nilai hasil pengamatan terhadap nilai sebenarnya, dihitung dengan formula berikut:

$$
R M S E=\sqrt{\frac{1}{n} \sum_{i=n}^{n}\left(y_{1}-y_{2}\right)^{2}}
$$


Dimana:

$\mathrm{y}_{1}=$ Data observasi

$\mathrm{y}_{2}=$ Data prakiraan

$\mathrm{n}$ = Jumlah data

RMSE didapatkan dari kuadrat selisih data observasi dan prakiraan dibagi dengan jumlah data yang diakarkan. Metode estimasi yang mempunyai RMSE lebih kecil dikatakan lebih akurat daripada metode estimasi yang mempunyai RMSE lebih besar [21].

\section{Analisis Data}

Data PM10 dari ECMWF yang telah diolah akan dibandingkan dengan data hasil pengukuran yang berada dalam rentang waktu yang sama yaitu bulan Februari s/d April 2020. Prediksi PM10 yang digunakan dalam penelitian ini adalah untuk prediksi tiga hari kedepan. Hasil prediksi dalam empat rentang waktu: $\mathrm{H}-3, \mathrm{H}-2, \mathrm{H}-1$, dan $\mathrm{H}-0$, akan digunakan sebagai acuan untuk melakukan verifikasi prediksi PM10. $\mathrm{H}$ disini adalah waktu dilakukannya pengukuran di lapangan, sementara angka yang menyertainya merupakan rentang waktu berapa hari ke depan nilai PM10 diprediksi. Misalnya $\mathrm{H}-3$ dapat diartikan sebagai hasil prediksi PM10 yang dilakukan tiga hari sebelumnya, atau untuk prediksi PM10 tiga hari ke depan dan seterusnya. Dalam hal ini, variasi rentang waktu digunakan untuk melihat keakuratan prediksi ECMWF terhadap yang terukur di lapangan.

\section{Hasil dan Pembahasan}

\section{Prediksi PM10 ECMWF dengan Data Observasi BAM 1020}

Data perbandingan hasil prediksi ECMWF dan observasi BAM 1020 sebanyak $87 \%$ dikarenakan ada beberapa data yang tidak tersedia. Gambar perbandingan konsentrasi PM10 berdasarkan hasil observasi BAM1020 dan prediksi ECMWF $\mathrm{H}-1, \mathrm{H}-2, \mathrm{H}-3$ dapat dilihat pada Gambar di bawah ini.

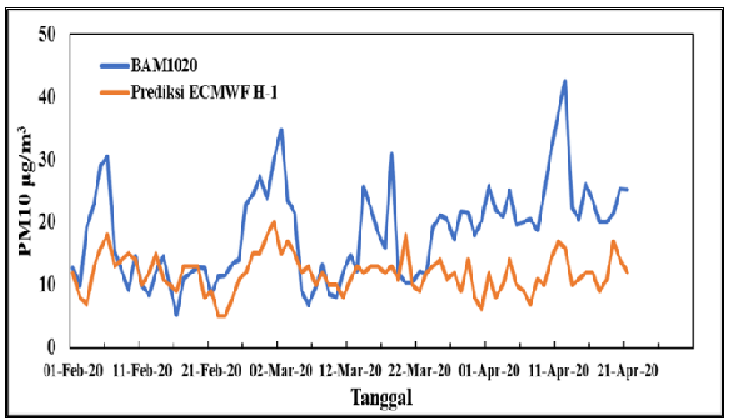

Gambar 1. Gambar perbandingan PM10 BAM1020 dengan data ECMWF H-1

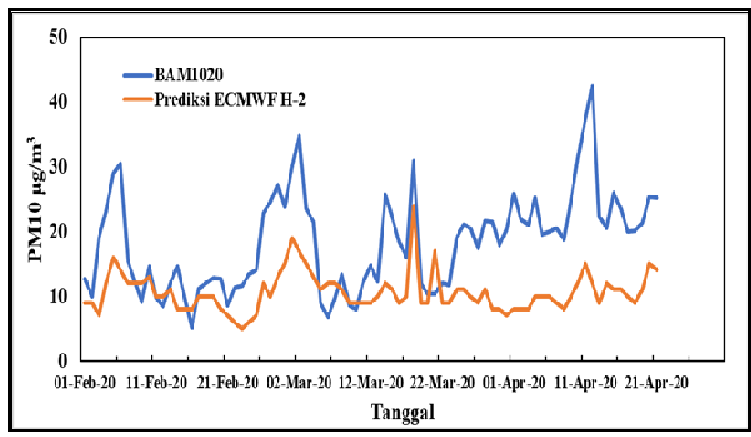

Gambar 2. Gambar perbandingan PM10 BAM1020 dengan data ECMWF H-2

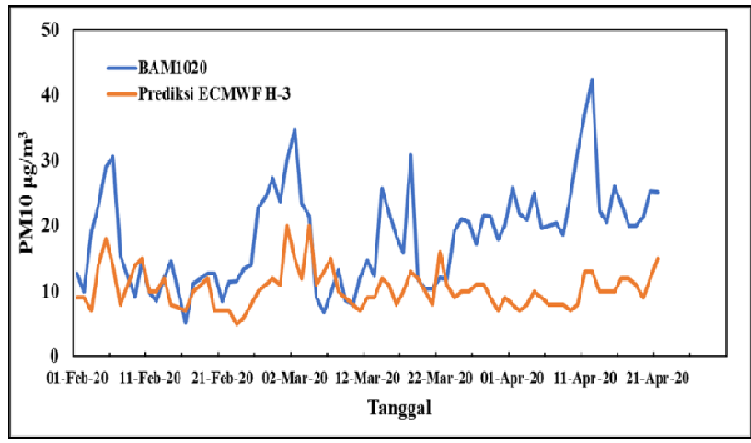

Gambar 3. Gambar perbandingan PM10 BAM 1020 dengan data ECMWF H-3

Berdasarkan hasil analisis prediksi PM10 ECMWF terhadap data observasi BAM 1020 pada tabel 1 , tabel 2 dan tabel 3 , secara ratarata data prediksi ECMWF memberikan hasil di bawah atau lebih kecil dari data observasi BAM 1020, hal ini memiliki kesesuaian jika dibandingkan dengan penelitian sebelumnya yang menyatakan bahwa pada kondisi normal tanpa adanya fenomena yang signifikan terhadap penyebab meningkatnya konsentrasi PM10 di udara ambien, maka model memberikan prediksi di bawah nilai yang teramati di observasi [22].

Konsentrasi maksimum dan minimum PM10 hasil observasi BAM 1020 dan prediksi ECMWF berdasarkan kategori, dapat dilihat pada Gambar dibawah ini.

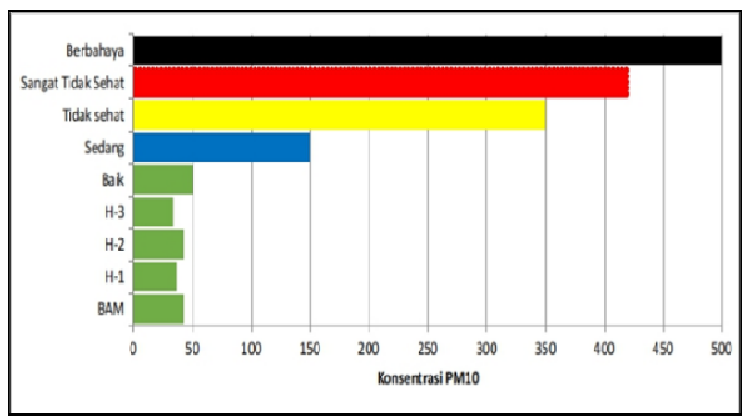

Gambar 4. Konsentrasi Maksimum PM10 BAM1020 Berdasarkan Kategori 


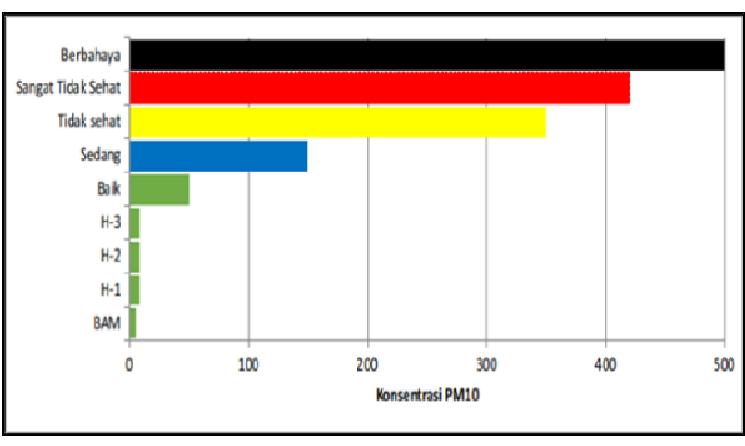

Gambar 5. Konsentrasi Minimum PM10 BAM1020 Berdasarkan Kategori

Pada Gambar 4, dan Gambar 5, konsentrasi maksimum dan minimum PM10 hasil prediksi ECMWF pada $\mathrm{H}-1, \mathrm{H}-2$ dan $\mathrm{H}-3$ berada pada kategori baik begitu juga konsentrasi maksimum dan minimum hasil observasi BAM 1020 juga pada kategori baik, semua hasil observasi dan hasil prediksi ini masih berada dibawah Baku Mutu Udara Ambien Nasional, sesuai dengan Peraturan Pemerintah Republik Indonesia Nomor 41 Tahun 1999, tentang Pengendalian Pencemaran Udara [23].

\section{Prediksi PM10 ECMWF dengan Data Observasi AQMS}

Data perbandingan hasil prediksi ECMWF dan hasil observasi di Kota Padang dengan menggunakan peralatan AQMS sebanyak $100 \%$. Gambar perbandingan konsentrasi PM10 berdasarkan hasil observasi AQMS dan prediksi ECMWF $\mathrm{H}-1, \mathrm{H}-2, \mathrm{H}-3$ dapat dilihat pada Gambar di bawah ini.

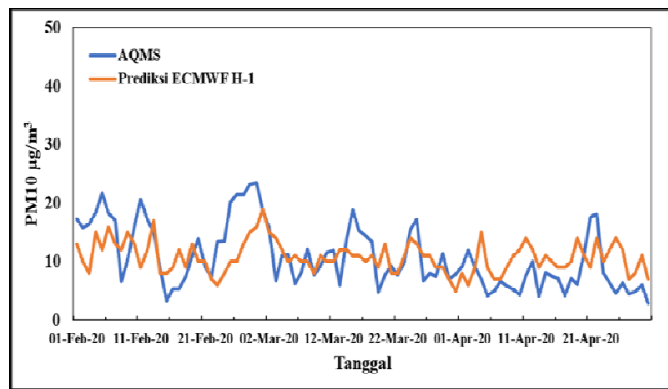

Gambar 6. Gambar perbandingan PM10 AQMS dengan data ECMWF $\mathrm{H}-1$

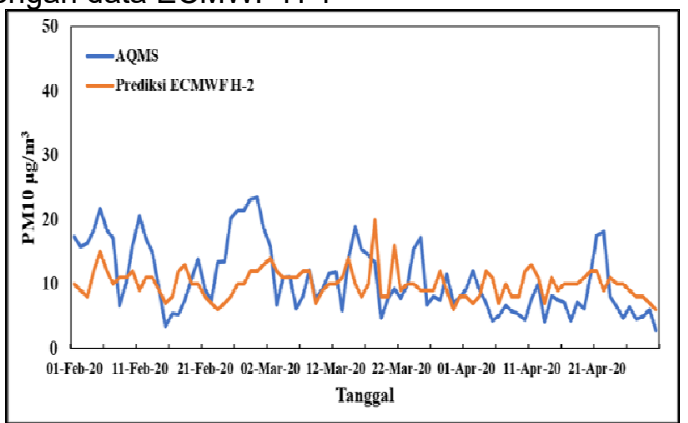

Gambar 7. Gambar perbandingan PM10 AQMS dengan data ECMWF H-2

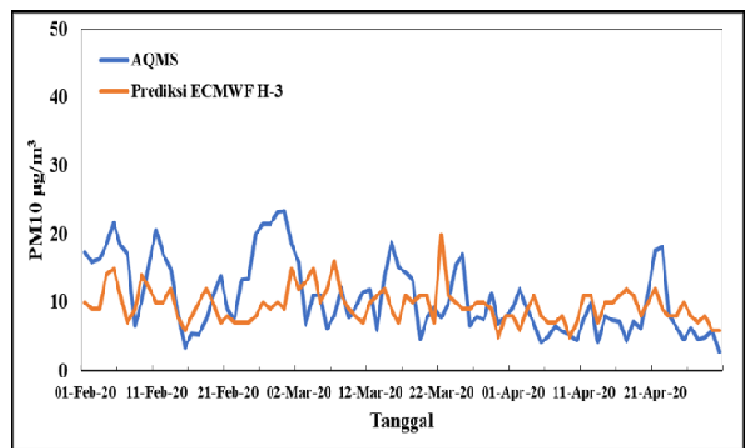

Gambar 8. Gambar perbandingan PM10 AQMS dengan data ECMWF H-3

Berdasarkan hasil analisis prediksi PM10 ECMWF terhadap data observasi AQMS pada tabel 6, tabel 7 dan tabel 8 , secara rata-rata data prediksi ECMWF memberikan hasil di atas atau lebih besar dari data observasi AQMS, secara berurutan nilai rata-rata prediksi ECMWF H-3 memiliki selisih lebih besar $17 \%$, nilai prediksi ECMWF H-2 lebih besar $20 \%$ dan nilai prediksi ECMWF $\mathrm{H}-1$ lebih besar $25 \%$ dari data observasi AQMS. Hasil yang didapatkan dari penelitian ini berbeda dengan hasil yang didapatkan dari penelitian sebelumnya, hal ini disebabkan banyak faktor yang mempengaruhi, antara lain, masa umur pakai peralatan observasi, faktor lingkungan yang sangat mempengaruhi dimana peralatan observasi tersebut dipasang, seperti gedung/bangunan tinggi, tumbuhan dan pohon tinggi yang menghalangi inlet dari peralatan observasi tersebut, yang mana menurut persyaratan SNI 19-7119.6-2005 butir 3.6.1 tentang ketentuan lokasi stasiun pemantau yang relatif dekat dengan bangunan atau pohon tertinggi [24]

Konsentrasi maksimum dan minimum PM10 hasil observasi AQMS dan prediksi ECMWF berdasarkan kategori, dapat dilihat pada Gambar dibawah ini.

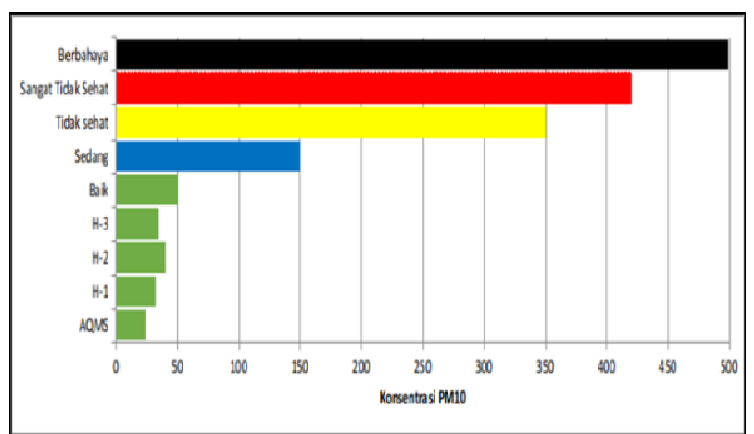

Gambar 9. Konsentrasi Maksimum PM10 AQMS Berdasarkan Kategori 


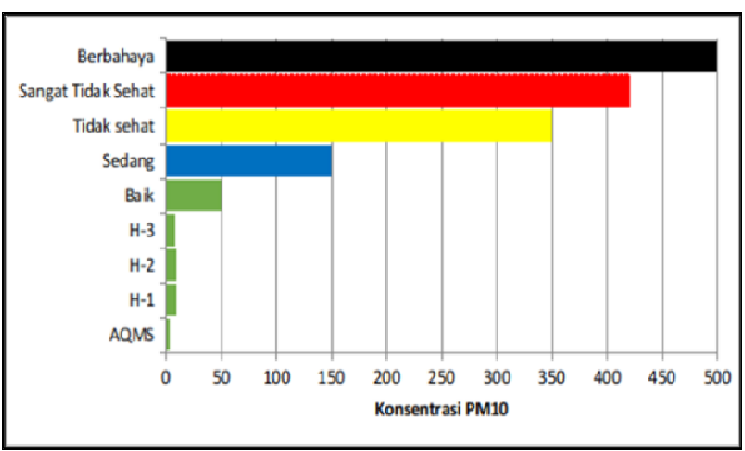

Gambar 10. Konsentrasi Minimum PM10 AQMS Berdasarkan Kategori

Pada Gambar 9, dan Gambar 10, konsentrasi maksimum dan minimum PM10 hasil prediksi ECMWF pada $\mathrm{H}-1, \mathrm{H}-2$ dan $\mathrm{H}-3$ berada pada kategori baik begitu juga konsentrasi maksimum dan minimum hasil observasi AQMS juga pada kategori baik, semua hasil observasi dan hasil prediksi ini masih berada dibawah Baku Mutu Udara Ambien Nasional, sesuai dengan Peraturan Pemerintah Republik Indonesia Nomor 41 Tahun 1999, tentang Pengendalian Pencemaran Udara dan Keputusan Kepala Badan Pengendalian Dampak Lingkungan tentang Pedoman Teknis Perhitungan dan Pelaporan serta Informasi Indeks Standar Pencemar Udara Nomor: KEP107/KABAPEDAL/11/1997 Tahun 1997 [25].

\section{Analisis Statistik Deskriptif}

Statistik deskriptif merupakan analisis statistik yang memberikan gambaran secara umum mengenai karakteristik dari masing-masing data penelitian yang dilihat dari nilai rata-rata (mean), nilai maksimum dan minimum, serta standar deviasi. Mean menunjukkan nilai ratarata data penelitian, sedangkan nilai minimum, maksimum, dan standar deviasi menunjukkan penyebaran data dari data penelitian yang digunakan [26]. Dalam penelitian ini, analisis statistik deskriptif dilakukan untuk data observasi BAM 1020, data observasi AQMS dan data prediksi PM10 ECMWF $\mathrm{H}-1, \mathrm{H}-2$ dan $\mathrm{H}-3$, data tersebut dapat dilihat pada tabel di bawah ini.

Berdasarkan tabel 1, hasil rata-rata analisis statistik deskriptif konsentrasi PM10 BAM 1020 dan prediksi ECMWF, pada hari kesatu lebih kecil dari hari kedua dan ketiga dengan nilai persentase secara berturut-turut $12 \%, 23 \%$ dan $24 \%$, hal ini memiliki kesesuaian jika dibandingkan dengan penelitian [22], yang mana pada kondisi normal tanpa adanya fenomena yang signifikan terhadap penyebab meningkatnya konsentrasi PM10 di udara ambien, maka model memberikan prediksi di bawah nilai yang teramati di observasi. Sedangkan hasil rata-rata analisis statistik deskriptif konsentrasi PM10 AQMS dan prediksi ECMWF berdasarkan tabel 2, pada hari kesatu lebih besar dari hari kedua dan hari ketiga, hal ini dikarenakan lokasi pengamatan di kota Padang berada di daerah urban/perkotaan sehingga banyak faktor yang mempengaruhi konsentrasi PM10 tersebut.

Tabel 1. Statistik Deskriptif Konsentrasi PM10 BAM1020 dan Prediksi ECMWF

\begin{tabular}{lccccccc}
\hline $\begin{array}{c}\text { Statistik } \\
\text { Deskriptif }\end{array}$ & $\begin{array}{c}\text { BAM } \\
\mathbf{1 0 2 0}\end{array}$ & H-1 & Selisih & H-2 & Selisih & H-3 & Selisih \\
\hline Minimum & 5,2 & 8,5 & $39 \%$ & 8,5 & $39 \%$ & 8,5 & $39 \%$ \\
Kuartil 1 & 12,1 & 14,1 & $14 \%$ & 13,0 & $7 \%$ & 12,5 & $3 \%$ \\
Median & 19,4 & 16,5 & $18 \%$ & 14,0 & $39 \%$ & 14,0 & $39 \%$ \\
Kuartil 3 & 23,4 & 18,5 & $27 \%$ & 16,6 & $41 \%$ & 17,0 & $38 \%$ \\
Max & 42,4 & 36,5 & $16 \%$ & 43,0 & $1 \%$ & 33,5 & $27 \%$ \\
Mean & 18,6 & 16,6 & $12 \%$ & 15,2 & $23 \%$ & 15,0 & $24 \%$ \\
Std Deviasi & 7,6 & & 4,1 & & 4,6 & & 4,1 \\
\hline
\end{tabular}

Tabel 2. Statistik Deskriptif Konsentrasi PM10 AQMS dan Prediksi ECMWF

\begin{tabular}{|c|c|c|c|c|c|c|c|}
\hline $\begin{array}{l}\text { Statistik } \\
\text { Deskriptif }\end{array}$ & AQMS & $\mathrm{H}-1$ & Selisih & $\mathrm{H}-2$ & Selisih & $\mathrm{H}-3$ & Selisih \\
\hline Minimum & 2,9 & 9,0 & $\begin{array}{c}- \\
68 \%\end{array}$ & 9,0 & $-68 \%$ & 8,0 & $-64 \%$ \\
\hline Kuartil 1 & 6,7 & 12,5 & $\begin{array}{c}- \\
47 \%\end{array}$ & 11,6 & $-43 \%$ & 11,0 & $-39 \%$ \\
\hline Median & 9,2 & 13,8 & $33 \%$ & 13,0 & $-30 \%$ & 12,5 & $-27 \%$ \\
\hline Kuartil 3 & 14,6 & 16,5 & $12 \%$ & 14,5 & $1 \%$ & 14,5 & $1 \%$ \\
\hline Max & 23,5 & 32,0 & $27 \%$ & 40,0 & $-41 \%$ & 34,5 & $-32 \%$ \\
\hline Mean & 10,8 & 14,5 & $25 \%$ & 13,5 & $-20 \%$ & 13,1 & $-17 \%$ \\
\hline Std Devias & 5,4 & \multicolumn{2}{|c|}{3,4} & \multicolumn{2}{|c|}{3,7} & \multicolumn{2}{|c|}{3,5} \\
\hline
\end{tabular}

Jika dibandingkan rata-rata keseluruhan data berdasarkan tabel 1 dan tabel 2, data observasi BAM 1020, yang merupakan data observasi daerah remote/background, berada diatas atau lebih tinggi dari data observasi AQMS di Kota Padang yang merupakan data observasi daerah urban/perkotaan, jika dikaitkan dengan penelitian sebelumnya yang menyatakan bahwa nilai konsentrasi PM10 untuk daerah urban/perkotaan lebih tinggi dari nilai konsentrasi PM10 untuk daerah remote/background [27], sedangkan hasil yang didapatkan dari penelitian ini berbeda dengan hasil yang didapatkan dari penelitian sebelumnya, hal ini disebabkan banyak faktor yang mempengaruhi, antara lain, masa umur pakai peralatan observasi, faktor lingkungan yang sangat mempengaruhi dimana peralatan 
observasi tersebut dipasang, seperti adanya gedung/bangunan tinggi, tumbuhan dan pohon tinggi yang menghalangi inlet dari peralatan observasi tersebut, sebagaimana yang persyaratkan menurut SNI 19-7119.6-2005.

\section{Analisis Data Bias (RMSE)}

Metode estimasi yang mempunyai RMSE lebih kecil dikatakan lebih akurat daripada metode estimasi yang mempunyai RMSE lebih besar [20]. Analisis Data Bias (RMSE) data observasi BAM1020 dan data observasi AQMS terhadap data prediksi PM10 ECMWF H-1, $\mathrm{H}-2$ dan $\mathrm{H}-3$, dapat dilihat pada tabel di bawah ini.

Tabel 3. Analisis Data Bias (RMSE) Data Observasi BAM 1020 Terhadap Data Prediksi ECMWF

\begin{tabular}{cc}
\hline $\begin{array}{c}\text { Data BAM 1020 Terhadap Data } \\
\text { Prediksi ECMWF }\end{array}$ & Nilai RMSE \\
\hline H-1 & 7,43 \\
H-2 & 8,19 \\
H-3 & 8,16 \\
\hline
\end{tabular}

Tabel 4. Analisis Data Bias (RMSE) Data Observasi AQMS Terhadap Data Prediksi ECMWF

\begin{tabular}{cc}
\hline $\begin{array}{c}\text { Data AQMS Terhadap Data } \\
\text { Prediksi ECMWF }\end{array}$ & Nilai RMSE \\
\hline H-1 & 6,37 \\
H-2 & 6,50 \\
H-3 & 6,35 \\
\hline
\end{tabular}

Dari hasil tabel 3 yang mana analisis data bias (RMSE), memberikan hasil dari $\mathrm{H}-1, \mathrm{H}-2$ dan $\mathrm{H}-$ 3 secara berturut-turut dengan nilai $7,43,8,19$ dan 8,16 , dan dapat diartikan data prediksi ECMWF $\mathrm{H}-1$ lebih akurat daripada $\mathrm{H}-2$ dan $\mathrm{H}$ 3 , terhadap data observasi, data ini seiring dengan data statistik deskriptif konsentrasi PM10 BAM 1020 dan prediksi ECMWF pada tabel 1 , sedangkan pada tabel 4 diketahui nilai analisis data bias (RMSE) $\mathrm{H}-1$ lebih besar daripada $\mathrm{H}-2$ dan $\mathrm{H}-3$, secara berturut-turut memberikan nilai $6,37,6,50$ dan 6,35 dan dapat diartikan data prediksi ECMWF $\mathrm{H}-1$ lebih kurang akurat daripada $\mathrm{H}-2$ dan $\mathrm{H}-3$, terhadap data observasi, data ini seiring dengan data statistik deskriptif konsentrasi AQMS dan prediksi ECMWF pada tabel 2.

\section{Kesimpulan}

Profil konsentrasi PM10 di Kota Padang menunjukkan variasi konsentrasi PM10 pada periode Februari sampai dengan April 2020, dengan rata-rata konsentrasi sebesar 10,8 $\mu \mathrm{g} / \mathrm{m}^{3}$, nilai maksimum $23,5 \mu \mathrm{g} / \mathrm{m}^{3}$, dan minimum sebesar $2,9 \mu \mathrm{g} / \mathrm{m}^{3}$. Sementara itu konsentrasi PM10 di Stasiun Pemantau Atmosfer Global Bukit Kototabang menunjukkan variasi konsentrasi dalam periode yang sama, dengan rata-rata konsentrasi PM10 sebesar $18,6 \mu \mathrm{g} / \mathrm{m}^{3}$, nilai maksimum 42,4 $\mu \mathrm{g} / \mathrm{m}^{3}$, dan minimum sebesar $5,2 \mu \mathrm{g} / \mathrm{m}^{3}$, hal ini berbanding terbalik dengan hasil penelitian yang pernah dilakukan sebelumnya.

Prediksi konsentrasi PM10 dengan menggunakan data ECMWF terhadap data observasi di kota Padang menunjukkan nilai selisih $25 \%(\mathrm{H}-1), 20 \%(\mathrm{H}-2)$, dan $17 \%(\mathrm{H}-3)$, dan nilai prediksi terbaik adalah untuk data prediksi ECMWF pada H-3. Sementara itu nilai prediksi konsentrasi PM10 dengan menggunakan data ECMWF terhadap data observasi di Stasiun Pemantau Atmosfer Global Bukit Kototabang menunjukan nilai $12 \%(\mathrm{H}-1)$, $23 \%(\mathrm{H}-2)$, dan $24 \%(\mathrm{H}-3)$. Hasil nilai prediksi terbaik konsentrasi PM10 di Stasiun Pemantau Atmosfer Global Bukit Kototabang adalah untuk data prediksi ECMWF pada $\mathrm{H}-1$.

\section{Daftar Pustaka}

[1] Annisa, D., 2016. Analisis Hubungan Konsentrasi Particulate Matter $10 \mu \mathrm{m}$ (PM10) di Udara Ambien Roadside Dengan Karakteristik Lalu Lintas Jaringan Jalan Primer Kota Padang. Disertasi Doktoral. Universitas Andalas.

[2] Chai, T. dan Draxler, R, R. 2014. Root mean square error (RMSE) or mean absolute error (MAE)? Arguments against avoiding RMSE in the literature. Geoscientific Model Development. 7: 1247-1250

[3] Dhilla, L., 2019. Analisis Risiko Kesehatan Lingkungan Pajanan PM10 Pada Pedagang Di Jalan Perintis Kemerdekaan Kota Padang Tahun 2018. Disertasi Doktoral, Universitas Andalas.

[4] Ghozali, Imam. 2018. Aplikasi Analisis Multivariate dengan Program IBM SPSS 25. Badan Penerbit Universitas Diponegoro: Semarang

[5] Ghozali, Imam. (2009). Aplikasi Analisis Multivariate Dengan Program SPSS. Semarang: Badan Penerbit Universitas Diponegoro.

[6] Giovanni, L., Ferrero, E., Karl, T., Rotach, M.W., Staquet, C., Trini Castelli, S. and Zardi, D., 2020. Atmospheric pollutant dispersion over complex terrain: Challenges and needs for improving air quality measurements and modeling. Atmosphere, 11(6), p.646.

[7] Goembira, F., Farnas, Z., Ihsan, T. and Djafri, D., 2020. Evaluation of PM 10 Concentrations in West Sumatra during Rainy Season. E\&ES, 448(1), p.012025.

[8] Gunawan, H., Ruslinda, Y., Bachtiar, V.S. and Dwinta, A., 2018. Model Hubungan Konsentrasi Particulate Matter $10 \mu \mathrm{m}$ (PM10) di Udara Ambien Dengan Karakteristik Lalu Lintas Di Jaringan Jalan Primer Kota Padang. Prosiding Semnastek.

[9] Gusti, A., Arlesia, A. and Anshari, L.H., 2018. Penurunan Derajat Kesehatan Pedagang Akibat Pajanan Debu PM10 di Kawasan Pasar Siteba Kota Padang. Media Kesehatan Masyarakat Indonesia, 14(3), pp.233-240.

[10] Ibrahim, M.H, Leh, F.C, Adnan, M, Isa, N.K.M, 2016, Pencemaran habuk di Malaysia: Mengesan taburan konsentrasi PM10 di pusat bandar, sub bandar dan 
pinggir bandar di Ipoh, Perak, Malaysian Journal of Society and Space 12 issue 5 (104 - 114).

[11] Iqbal, M., 2017. Pengaruh Arah Angin terhadap Dispersi Konsentrasi Particulate Matter 10 (PM10) pada Udara Roadside di Kota Padang. Disertasi Doktoral. Universitas Andalas.

[12] Keputusan Kepala Badan Pengendalian Dampak Lingkungan Nomor: KEP-107/KABAPEDAL/11/1997 Tahun 1997, tentang Pedoman Teknis Perhitungan dan Pelaporan serta Informasi Indeks Standar Pencemar Udara

[13] Kurniawan, A., 2017. Pengukuran Parameter Kualitas Udara (CO, NO2, SO2, O3 dan PM10) Di Bukit Kototabang Berbasis Ispu. Jurnal Teknosains, 7(1), pp.1-13.

[14] Kuwata, M., Neelam-Naganathan, G.G., Miyakawa, T., Khan, M.F., Kozan, O., Kawasaki, M., Sumin, S. and Latif, M.T., 2018. Constraining the emission of particulate matter from Indonesian peatland burning using continuous observation data. Journal of Geophysical Research: Atmospheres, 123(17), pp.9828-9842.

[15] Lamarque, J. F., et al. (2010), Historical (1850-2000) gridded anthropogenic and biomass burning emissions of reactive gases and aerosols: Methodology and application, Atmos. Chem. Phys. 10(15), 7017-7039, doi:10.5194/acp-10-7017-2010.

[16] Nurkholis, A., Rahma, A.D., Widyaningsih, Y., Maretya, D.A., Wangge, G.A., Widiastuti, A.S., Suci, A. and Abdillah, A., 2018. Analisis Temporal Kebakaran Hutan dan Lahan di Indonesia Tahun 1997 dan 2015 (Studi Kasus Provinsi Riau).

[17] PP RI Nomor 41 Tahun (1999), tentang Pengendalian Pencemaran Udara. Kementrian Lingkungan Hidup: Jakarta.

[18] Putra, I.K., Saharjo, B.H. and Wasis, B., 2019 Tantangan kelembagaan pengendalian kebakaran hutan dan lahan pada tingkat tapak. Jurnal IImu Pertanian Indonesia, 24(2), pp.151-159.

[19] Randa, A., 2017. Validasi konsentrasi polutan PM10 $\mathrm{CO}, \mathrm{NO} 2$ dan $\mathrm{SO} 2$ akibat pengaruh arah angin pada udara roadside di kota padang. Disertasi Doktoral. Universitas Andalas.

[20] Robinson, T.P., G. Metternicht., 2006, Testing the performance of spatial interpolation techniques for mapping soil properties, Computer and Electronics in Agriculture 50.

[21] Roland R. Draxler, Dale A. Gillette, Jeffrey S. Kirkpatrick, Jack Heller. (2001). Estimating $P M_{10}$ air concentration from dust storms in Iraq, Kuwait and Saudi Arabia. Atmospheric Environment Vol.35/Hal. 4315-4330. Elsevier Science Ltd.

[22] Seinfeld, J.H. and Pandis, S.N., 2016. Atmospheric chemistry and physics: from air pollution to climate change. John Wiley \& Sons.Shaw, G. E., 1988. Aerosol-size temperature relationship, Geophys. Res. Lett., 15, 133-135.

[23] Standar Nasional Indonesia. 2005. SNI Nomor SNI 19-7119.6-2005 tentang Udara ambien - Bagian 6: Penentuan lokasi pengambilan contoh uji pemantauan kualitas udara ambien. Badan Standarisasi Nasional. Jakarta.

[24] Stirnberg, R., Cermak, J., Fuchs, J. and Andersen, $\mathrm{H} ., 2019$, January. Understanding driving factors of ground PM10 concentrations using satellite $A O D$ and a machine learning approach. In Geophysical Research Abstracts (Vol. 21).

[25] Suci, M.Y., 2018. Pengaruh Faktor Meteorologi dan Karakteristik Lalu Lintas Terhadap Disersi Konsentrasi Particulate Matter 10 (PM10) Pada Udara Roadside Malam Hari di Kota Padang. Disertasi Doktoral, Universitas Andalas.

[26] Thalia, H.G., 2019. Analisis Risiko Kesehatan Lingkungan Pajanan PM 10 Terhadap Pedagang Kaki
Lima di Pasar Kota Payakumbuh Tahun 2018. Disertasi Doktoral. Universitas Andalas.

[27] Wahidmurni. (2017). Pemaparan Metode Penelitian Kualitatif. UIN Maulana Malik Ibrahim Malang, (6), 67-72.

[28] World Health Organization (WHO) 2016. Health and the environment: draft road map for an enhanced global response to the adverse health effects of air pollution: report by the Secretariat, WHO. Geneva. 